\title{
Inguinal Hernia without Mention of Obstruction or Gangrene
}

National Cancer Institute

\section{Source}

National Cancer Institute. Inguinal Hernia without Mention of Obstruction or Gangrene. NCl Thesaurus. Code C34728.

The protrusion of abdominal cavity contents through the inguinal canal, without mention of obstruction or necrosis of the herniated contents. 